\title{
Front Matter: Volume 7263
}

, "Front Matter: Volume 7263," Proc. SPIE 7263, Medical Imaging 2009: Image Perception, Observer Performance, and Technology Assessment, 726301 (24 March 2009); doi: 10.1117/12.829529

Event: SPIE Medical Imaging, 2009, Lake Buena Vista (Orlando Area), Florida, United States 


\title{
Medical Imaging 2009
}

\section{Image Perception, Observer Performance, and Technology Assessment}

\author{
Berkman Sahiner \\ David J. Manning \\ Editors
}

11-12 February 2009

Lake Buena Vista, Florida, United States

Sponsored by

SPIE

Cooperating Organizations

AAPM-American Association of Physicists in Medicine (United States)

APS-American Physiological Society (United States)

CARS - Computer Assisted Radiology and Surgery (Germany)

IS\&T-The Society for Imaging Science and Technology

MIPS-Medical Image Perception Society (United States)

RSNA-Radiological Society of North America (United States)

SIIM-Society for Imaging Informatics in Medicine (United States)

SMI-The Society for Molecular Imaging

The DICOM Standards Committee (United States)

Published by

SPIE

Volume 7263

Proceedings of SPIE, 1605-7422, v. 7263

SPIE is an international society advancing an interdisciplinary approach to the science and application of light. 
The papers included in this volume were part of the technical conference cited on the cover and title page. Papers were selected and subject to review by the editors and conference program committee. Some conference presentations may not be available for publication. The papers published in these proceedings reflect the work and thoughts of the authors and are published herein as submitted. The publisher is not responsible for the validity of the information or for any outcomes resulting from reliance thereon.

Please use the following format to cite material from this book:

Author(s), "Title of Paper," in Medical Imaging 2009: Image Perception, Observer Performance, and Technology Assessment, edited by Berkman Sahiner, David J. Manning, Proceedings of SPIE Vol. 7263 (SPIE, Bellingham, WA, 2009) Article CID Number.

ISSN 1605-7422

ISBN 9780819475145

Published by

SPIE

P.O. Box 10, Bellingham, Washington 98227-0010 USA

Telephone +1 3606763290 (Pacific Time) · Fax +1 3606471445

SPIE.org

Copyright (C) 2009, Society of Photo-Optical Instrumentation Engineers.

Copying of material in this book for internal or personal use, or for the internal or personal use of specific clients, beyond the fair use provisions granted by the U.S. Copyright Law is authorized by SPIE subject to payment of copying fees. The Transactional Reporting Service base fee for this volume is $\$ 18.00$ per article (or portion thereof), which should be paid directly to the Copyright Clearance Center (CCC), 222 Rosewood Drive, Danvers, MA 01923. Payment may also be made electronically through CCC Online at copyright.com. Other copying for republication, resale, advertising or promotion, or any form of systematic or multiple reproduction of any material in this book is prohibited except with permission in writing from the publisher. The CCC fee code is 1605 $7422 / 09 / \$ 18.00$.

Printed in the United States of America.

Publication of record for individual papers is online in the SPIE Digital Library.

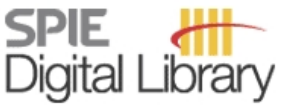

SPIEDigitallibrary.org

Paper Numbering: Proceedings of SPIE follow an e-First publication model, with papers published first online and then in print and on CD-ROM. Papers are published as they are submitted and meet publication criteria. A unique, consistent, permanent citation identifier (CID) number is assigned to each article at the time of the first publication. Utilization of CIDs allows articles to be fully citable as soon they are published online, and connects the same identifier to all online, print, and electronic versions of the publication. SPIE uses a six-digit CID article numbering system in which:

- The first four digits correspond to the SPIE volume number.

- The last two digits indicate publication order within the volume using a Base 36 numbering system employing both numerals and letters. These two-number sets start with 00, 01, 02, 03, 04, $05,06,07,08,09,0 \mathrm{~A}, 0 \mathrm{~B} \ldots \mathrm{OZ}$, followed by 10-1Z, 20-2Z, etc.

The CID number appears on each page of the manuscript. The complete citation is used on the first page, and an abbreviated version on subsequent pages. Numbers in the index correspond to the last two digits of the six-digit CID number. 


\section{Contents}

$\begin{aligned} \text { xi } & \text { Conference Committee } \\ \text { xiii } & \text { In Memoriam: Robert F. Wagner (1938-2008) }\end{aligned}$

SESSION 1 NOVEL TOOLS AND OPTIMIZATION

726302 Optimization of exposure index values for the antero-posterior pelvis and antero-posterior knee examination [7263-01]

M. L. Butler, L. Rainford, J. Last, P. C. Brennan, School of Medicine and Medical Science, Univ. College Dublin (Ireland)

726303 Histopathology reconstruction on digital imagery [7263-02]

W. Li, STI Medical Systems (United States); R. W. Lieberman, Univ. of Michigan Medical School (United States); S. Nie, Y. Xie, M. Eldred, J. Oyama, STI Medical Systems (United States)

726304 A novel teaching tool using dynamic cues improves visualisation of chest lesions by naive observers [7263-03]

M. A. Mohamed Ali, R. J. Toomey, J. T. Ryan, School of Medicine and Medical Sciences, Univ. College Dublin (Ireland); F. C. Cuffe, Univ. College Dublin (Ireland); P. C. Brennan, School of Medicine and Medical Sciences, Univ. College Dublin (Ireland)

726305 Validation of an improved abnormality insertion method for medical image perception investigations [7263-04]

M. T. Madsen, G. R. Durst, R. T. Caldwell, K. M. Schartz, B. H. Thompson, K. S. Berbaum, The Univ. of lowa (United States)

$726306 \quad$ Motion and display effects on perception of multiple coronary stents [7263-05]

S. Zhang, Univ. of California, Santa Barbara (United States); C. K. Abbey, Univ. of California, Santa Barbara (United States) and Univ. of California, Davis (United States); A. Teymoorian, Univ. of California, Santa Barbara (United States); X. Da, J. S. Whiting, Cedars-Sinai Medical Ctr. (United States); M. P. Eckstein, Institute for Collaborative Biotechnology, Univ. of California, Santa Barbara (United States)

\section{SESSION 2 IMAGE DISPLAY}

726307 The impact of faceplate surface characteristics on detection of pulmonary nodules [7263-06]

R. J. Toomey, J. T. Ryan, M. F. McEntee, J. McNulty, School of Medicine and Medical Science, Univ. College Dublin (Ireland); M. G. Evanoff, The American Board of Radiology (United States); F. Cuffe, Univ. College Dublin (Ireland); T. Yoneda, Eizo Nanao Corp. (Japan); J. Stowe, P. C. Brennan, School of Medicine and Medical Science, Univ. College Dublin (Ireland)

726308 Clinical validation of a medical grade color monitor for chest radiology [7263-07] J. Jacobs, F. Zanca, J. Verschakelen, G. Marchal, H. Bosmans, Univ. Hospital Gasthuisberg (Belgium) 
726309 Spatial noise suppression for LCD displays [7263-08]

W. J. Dallas, H. Roehrig, The Univ. of Arizona (United States); J. Fan, GE Healthcare (United

States); E. A. Krupinski, The Univ. of Arizona (United States); J. P. Johnson, Siemens Corporate Research (United States)

7263 OA Performance evaluation of a full line of medical diagnostic displays and test of a web-based service for remote calibration and quality assurance [7263-09]

S. Busoni, G. Belli, A. Taddeucci, S. Targetti, I. Menchi, C. Gori, L. Capaccioli, A. Falivene, G. Spanò, A. Guasti, P. Saletti, F. Rossi, Azienda Ospedaliero-Universitaria Careggi (Italy)

$7263 \mathrm{OB}$ Impact of luminance distribution in the visual field on foveal contrast sensitivity in the context of mammographic softcopy reading [7263-10]

D. Apelt, MeVis BreastCare Solutions GmbH \& Co. KG (Germany); R. Rascher-Friesenhausen, J. Klein, Fraunhofer MEVIS (Germany); H. Strasburger, Univ. of Göttingen (Germany); B. Preim, Otto-von-Guericke Univ. (Germany); H.-O. Peitgen, Fraunhofer MEVIS (Germany)

7263 OC High-quality remote interactive imaging in the operating theatre [7263-11] I. J. Grimstead, N. J. Avis, Cardiff Univ. (United Kingdom); P. L. Evans, A. Bocca, Morriston Hospital (United Kingdom)

SESSION 3 MEDICAL IMAGING AND RADIOLOGICAL HEALTH: CONTRIBUTIONS OF DR. ROBERT F. WAGNER

7263 OD Bob's first decade: in at the beginning (Keynote Paper) [7263-12]

D. G. Brown, Ctr. for Devices and Radiological Health, FDA (United States)

7263 OE Statistical ultrasonics: the influence of Robert F. Wagner (Keynote Paper) [7263-13]

M. F. Insana, Univ. of Illinois at Urbana-Champaign (United States)

7263 OF NEQ: its progenitors and progeny (Keynote Paper) [7263-14]

H. H. Barrett, College of Optical Sciences, The Univ. of Arizona (United States)

7263 OG Performance-based assessment of reconstructed images (Keynote Paper) [7263-15]

K. M. Hanson, Los Alamos National Lab. (United States)

$7263 \mathrm{OH} \quad$ Finding order in complexity: themes from the career of Dr. Robert F. Wagner (Keynote Paper) [7263-16]

K. J. Myers, CDRH, U.S. Food and Drug Administration (United States)

\section{SESSION 4 EYE TRACKING AND HUMAN VISUAL SYSTEM}

7263 ol Spatial frequency characteristics at image decision-point locations for observers with different radiological backgrounds in lung nodule detection [7263-17]

M. W. Pietrzyk, Univ. of Cumbria (United Kingdom) and Lancaster Univ. (United Kingdom);

D. J. Manning, Univ. of Cumbria (United Kingdom); A. Dix, Lancaster Univ. (United Kingdom);

T. Donovan, Univ. of Cumbria (United Kingdom)

7263 0J Modeling decision-making in single- and multi-modal medical images [7263-18]

R. L. Canosa, Rochester Institute of Technology (United States); K. G. Baum, Biomedical and Materials Multimodal Imaging Lab., Rochester Institute of Technology (United States) 
7263 OK Radiology image perception and observer performance: How does expertise and clinical information alter interpretation? Stroke detection explored through eye-tracking [7263-19] L. Cooper, A. Gale, I. Darker, Loughborough Univ. (United Kingdom); A. Toms, Norwich Radiology Academy (United Kingdom); J. Saada, Norfolk and Norwich Univ. Hospitals NHS Trust (United Kingdom)

$7263 \mathrm{OL}$ The holistic grail: possible implications of an initial mistake in the reading of digital mammograms [7263-20]

C. Mello-Thoms, Univ. of Pittsburgh (United States)

$72630 \mathrm{M}$ Activity in the fusiform face area supports expert perception in radiologists and does not depend upon holistic processing of images [7263-21]

S. A. Engel, Univ. of Minnesota (United States); E. M. Harley, Exponent, Inc. (United States); W. B. Pope, J. P. Villablanca, J. C. Mazziotta, D. Enzmann, David Geffen School of Medicine at UCLA (United States)

$7263 \mathrm{ON} \quad$ Visually lossless compression of breast biopsy virtual slides for telepathology [7263-22] J. P. Johnson, Siemens Corporate Research (United States); E. A. Krupinski, The Univ. of Arizona (United States); J. S. Nafziger, Embry-Riddle Aeronautical Univ. (United States); M. Yan, Siemens Corporate Research (United States); H. Roehrig, The Univ. of Arizona (United States)

\section{SESSION 5 MODEL OBSERVERS}

726300 Mass detection in breast tomosynthesis and digital mammography: a model observer study [7263-23]

C. Castella, Univ. Institute for Radiation Physics, CHUV and Univ. Lausanne (Switzerland) and LPHE, EPFL (Switzerland); M. Ruschin, Princess Margaret Hospital (Canada); M. P. Eckstein, C. K. Abbey, Univ. of California, Santa Barbara (United States); K. Kinkel, Clinique des Grangettes (Switzerland); F. R. Verdun, Univ. Institute for Radiation Physics, CHUV and Univ. Lausanne (Switzerland); A. Tingberg, Lund Univ., Malmö Univ. Hospital (Sweden); F. O. Bochud, Univ. Institute for Radiation Physics, CHUV and Univ. Lausanne (Switzerland)

7263 OP Optimization of medical imaging display systems: using the channelized Hotelling observer for detecting lung nodules: experimental study [7263-24] L. Platiša, E. Vansteenkiste, B. Goossens, Gent Univ. (Belgium); C. Marchessoux, T. Kimpe, Barco N.V. (Belgium); W. Philips, Gent Univ. (Belgium)

$72630 Q \quad$ Using partial least squares to compute efficient channels for the Bayesian ideal observer [7263-25]

J. M. Witten, Univ. of Maryland, College Park (United States) and U.S. Food and Drug Administration (United States); S. Park, K. J. Myers, CDRH, U.S. Food and Drug Administration (United States)

7263 OR Tests of scanning model observers for myocardial SPECT imaging [7263-26]

H. C. Gifford, P. H. Pretorius, Univ. of Massachusetts Medical School (United States);

J. G. Brankov, Illinois Institute of Technology (United States) 
7263 OS On ideal AFROC and FROC observers [7263-27]

P. Khurd, Philips Healthcare (United States); B. Liu, G. Gindi, Medical Image Processing Lab.

Stony Brook Univ. (United States)

SESSION 6 ROC

7263 OT JAFROC analysis revisited: figure-of-merit considerations for human observer studies

[7263-28]

D. P. Chakraborty, H.-J. Yoon, Univ. of Pittsburgh (United States)

7263 OU Non-localization and localization ROC analyses using clinically based scoring [7263-29] S. Paquerault, F. W. Samuelson, K. J. Myers, R. C. Smith, U.S. Food and Drug Administration (United States)

7263 OV Comparison of ROC methods for partially paired data [7263-30]

B. D. Gallas, FDA, Ctr. for Devices and Radiological Health (United States); L. L. Pesce, The Univ. of Chicago (United States)

7263 OW Comparing the performance of two observers using a novel utility based performance metric for ROC analysis [7263-31]

D. C. Edwards, C. E. Metz, The Univ. of Chicago (United States)

7263 OX Comparison of classifier performance estimators: a simulation study [7263-32]

W. Chen, R. F. Wagner, W. A. Yousef, B. D. Gallas, CDRH, U.S. Food and Drug Administration (United States)

7263 OY A theoretical treatment of the sources of variability in the output of pattern classifiers [7263-33]

S. Gupta, Texas Instruments Inc. (United States); M. K. Markey, The Univ. of Texas at Austin (United States)

\section{SESSION 7 OBSERVER PERFORMANCE}

$7263 \mathrm{OZ} \quad$ Evaluation of chest tomosynthesis for the detection of pulmonary nodules: effect of clinical experience and comparison with chest radiography [7263-34]

S. Zachrisson, J. Vikgren, A. Svalkvist, Å. A. Johnsson, M. Boijsen, A. Flinck, L. G. Månsson,

S. Kheddache, M. Båth, Univ. of Gothenburg (Sweden) and Sahlgrenska Univ. Hospital

(Sweden)

726310 Correlation of emphysema score with perceived malignancy of pulmonary nodules: a multi-observer study using the LIDC-IDRI CT lung database [7263-35]

R. Wiemker, T. Bülow, T. Blaffert, Philips Research Europe (Germany); E. Dharaiya, Philips Medical System CT (United States)

726311 The effect of digitising film prior mammograms on radiologists' performance in breast screening: a JAFROC study [7263-36]

S. Taylor-Phillips, Loughborough Univ. (United Kingdom); M. G. Wallis, Addenbrooke's Hospital (United Kingdom); A. Duncan, Univ. Hospital Coventry (United Kingdom);

A. G. Gale, Loughborough Univ. (United Kingdom) 
726312 The impact of focal spot size on clinical images [7263-37]

S. M. Gorham, P. C. Brennan, School of Medicine and Medical Science, Univ. College

Dublin (Ireland)

726313 Contrast detail curves in head CT examinations [7263-38]

S. Elojeimy, W. Huda, Medical Univ. of South Carolina (United States); K. M. Ogden, SUNY Upstate Medical Univ. (United States); R. Owen, Medical Univ. of South Carolina (United States); E. Samei, Duke Univ. Medical Ctr. (United States); Z. Rumboldt, Medical Univ. of South Carolina (United States)

\section{SESSION 8 OBSERVER PERFORMANCE IN MAMMOGRAPHY}

726314 Analysis of probed regions in an interactive CAD system for the detection of masses in mammograms [7263-39]

M. Samulski, A. Hupse, C. Boetes, Radboud Univ. Nijmegen Medical Ctr. (Netherlands); G. den Heeten, National Expert and Training Ctr. for Breast Cancer Screening, Radboud Univ. Nijmegen Medical Ctr. (Netherlands); N. Karssemeijer, Radboud Univ. Nijmegen Medical Ctr. (Netherlands)

726315 Inter- and intra-observer variability in radiologists' assessment of mass similarity on mammograms [7263-40]

B. Sahiner, L. M. Hadjiiski, H.-P. Chan, J. Cui, C. Paramagul, A. Nees, M. Helvie, Univ. of Michigan (United States)

726316 Analysis of double reading in an observer study [7263-41]

Y. Jiang, The Univ. of Chicago (United States)

726317 Higher-order scene statistics of breast images [7263-42]

C. K. Abbey, Univ. of California, Santa Barbara (United States) and Univ. of California, Davis (United States); J. N. Sohl-Dickstein, B. A. Olshausen, Univ. of California, Berkeley (United States); M. P. Eckstein, Univ. of California, Santa Barbara (United States); J. M. Boone, Univ. of California, Davis (United States) and UC Davis Medical Ctr. (United States)

726318 Contrast sensitivity in mammographic softcopy reading [7263-43]

D. Apelt, MeVis BreastCare Solutions GmbH \& Co. KG (Germany); H. Strasburger, Univ. of Göttingen (Germany); R. Rascher-Friesenhausen, J. Klein, Fraunhofer MEVIS (Germany); B. Preim, Otto-von-Guericke Univ. (Germany); H.-O. Peitgen, Fraunhofer MEVIS (Germany)

726319 Can the evaluation of a simple test object be used to predict the performance of a contrast-detail analysis in digital mammography? [7263-44]

H. Bosmans, K. Lemmens, J. Jacobs, Univ. Hospitals of the KU Leuven (Belgium);

D. Vandenbroucke, Agfa Healthcare (Belgium); F. Zanca, K. Michielsen, B. Verbrugge,

K. Smans, G. Marchal, Univ. Hospitals of the KU Leuven (Belgium)

\section{POSTER SESSION}

$72631 \mathrm{~A} \quad$ Automated scoring method for the CDMAM phantom [7263-45]

M. Yip, W. Chukwu, E. Kottis, E. Lewis, Univ. of Surrey (United Kingdom); J. Oduko,

O. Gundogdu, K. C. Young, National Coordinating Ctr. for the Physics of Mammography, Royal Surrey County Hospital (United Kingdom); K. Wells, Univ. of Surrey (United Kingdom) 
7263 IB Recognition of detail in mammography [7263-46]

D. Apelt, MeVis BreastCare Solutions GmbH \& Co. KG (Germany); H. Strasburger, Univ. of Göttingen (Germany); R. Rascher-Friesenhausen, J. Klein, Fraunhofer MEVIS (Germany);

B. Preim, Otto-von-Guericke Univ. (Germany); H.-O. Peitgen, Fraunhofer MEVIS (Germany)

7263 1C Mammographic interpretation training in the UK: current difficulties and future outlook [7263-47]

Y. Chen, A. G. Gale, H. Scott, Loughborough Univ. (United Kingdom)

7263 ID Reading the lesson: eliciting requirements for a mammography training application [7263-48]

M. Hartswood, Univ. of Edinburgh (United Kingdom); L. Blot, P. Taylor, Univ. College London (United Kingdom); S. Anderson, Univ. of Edinburgh (United Kingdom); R. Procter, Manchester Univ. (United Kingdom); L. Wilkinson, St. George's Hospital NHS Trust (United Kingdom); L. Smart, South East Scotland Breast Screening Ctr. (United Kingdom)

$72631 \mathrm{E}$ The relationship between real life breast screening and an annual self assessment scheme [7263-49]

H. J. Scott, Loughborough Univ. (United Kingdom); A. Evans, Nottingham International Breast Education Ctr., Nottingham City Hospital (United Kingdom); A. G. Gale, Loughborough Univ. (United Kingdom); A. Murphy, J. Reed, Nottingham International Breast Education Ctr.,

Nottingham City Hospital (United Kingdom)

$7263 \mathrm{IF}$ Developing and testing a multi-probe resonance electrical impedance spectroscopy system for detecting breast abnormalities [7263-50]

D. Gur, B. Zheng, Univ. of Pittsburgh (United States); S. Dhurjaty, G. Wolfe, Dhurjaty Electronics Consulting LLC (United States); M. Fradin, Fradin Consulting LLC (United States); R. Weil, Dhurjaty Electronics Consulting LLC (United States); J. Sumkin, M. Zuley, Univ. of Pittsburgh (United States)

7263 IG ViewDEX 2.0: a Java-based DICOM-compatible software for observer performance studies [7263-51]

M. Håkansson, Södra Älvsborgs Sjukhus (Sweden) and Univ. of Gothenburg (Sweden); S. Svensson, Sahlgrenska Univ. Hospital (Sweden); S. Zachrisson, A. Svalkvist, M. Båth,

L. G. Månsson, Univ. of Gothenburg (Sweden) and Sahlgrenska Univ. Hospital (Sweden)

7263 1H Ambient temperature variation affects radiological diagnostic performance [7263-52] M. McEntee, School of Medicine and Medical Science, Health Sciences Ctr., Univ. College Dublin (Ireland); S. Gafoor, Temple Street Hospital (Ireland)

$726311 \quad$ Improving mouse pointing for radiology tasks [7263-53]

Y. Tan, G. Tien, B. Forster, M. S. Atkins, Simon Fraser Univ. (Canada) and Univ. of British Columbia (Canada)

7263 1K Quality control evaluation of 37 liquid crystal displays used in diagnostic services [7263-55] J. J. Morant, Univ. Rovira i Virgili (Spain); M. Chevalier, E. Guibelalde, Univ. Complutense Madrid (Spain); M. E. Brandan, Univ. Complutense Madrid (Spain) and Univ. Nacional Autónoma de México (Mexico)

7263 IL Content-based versus semantic-based retrieval: an LIDC case study [7263-56] S. A. Jabon, Rose-Hulman Institute of Technology (United States); D. S. Raicu, J. D. Furst, DePaul Univ. (United States) 
$72631 \mathrm{M} \quad$ Reverse hierarchy theory and medical image perception [7263-57]

T. Donovan, D. J. Manning, School of Medical Imaging Sciences, Univ. of Cumbria (United Kingdom)

7263 iN Selective evaluation of noise, blur, and aliasing artifacts in fast MRI reconstructions using a weighted perceptual difference model: Case-PDM (Cum Laude Poster Award) [7263-58] J. Miao, Case Western Reserve Univ. (United States); D. L. Wilson, Univ. Hospitals of Cleveland \& Case Western Reserve Univ. (United States)

726310 Impact of visual fatigue on observer performance [7263-59] E. A. Krupinski, The Univ. of Arizona (United States); K. S. Berbaum, R. Caldwell, The Univ. of lowa (United States)

7263 IP Effectiveness of computer aided detection for solitary pulmonary nodules [7263-60] J. Yan, Carestream Health Global R\&D (China); W. Li, Carestream Health Global R\&D (China) and Shanghai Jiaotong Univ. (China); X. Du, Xuanwu Hospital of Capital Medical Univ. (China); H. Lu, Carestream Health Global R\&D (China); J. XU, Renji Hospital of Shanghai Jiaotong Univ. (China); M. XU, Carestream Health Global R\&D (China); D. Rong, Xuanwu Hospital of Capital Medical Univ. (China)

$72631 Q$ Lung nodule detection in chest radiography: image components analysis [7263-61] T. Luo, X. Mou, Y. Yang, H. Yan, Xi'an Jiaotong Univ. (China)

7263 IR A study on the effect of $\mathrm{CT}$ imaging acquisition parameters on lung nodule image interpretation [7263-62]

S. J. YU, Univ. of Southern California (United States); J. S. Wantroba, D. S. Raicu, J. D. Furst, DePaul Univ. (United States); D. S. Channin, Northwestern Univ. (United States);

S. G. Armato III, The Univ. of Chicago (United States)

$72631 \mathrm{~T}$ Scanning model observers to predict human performance in LROC studies of SPECT reconstruction using anatomical priors (Honorable Mention Poster Award) [7263-64] A. Lehovich, H. C. Gifford, M. A. King, Univ. of Massachusetts Medical School (United States)

$72631 \mathrm{U}$ Singular value decomposition of pinhole SPECT systems [7263-65]

R. Palit, College of Optical Sciences, The Univ. of Arizona (United States); M. A. Kupinski, H. H. Barrett, E. W. Clarkson, College of Optical Sciences, The Univ. of Arizona (United States) and The univ. of Arizona (United States); J. N. Aarsvold, Emory Univ. (United States); L. Volokh, Y. Grobshtein, GE Healthcare (Israel)

7263 IW Is Grannum grading of the placenta reproducible? [7263-67]

M. Moran, J. Ryan, P. C. Brennan, School of Medicine and Medical Science, Univ. College Dublin (Ireland); M. Higgins, F. M. McAuliffe, School of Medicine and Medical Science, Univ. College Dublin (Ireland) and National Maternity Hospital (Ireland)

Author Index 
Downloaded From: https://www.spiedigitallibrary.org/conference-proceedings-of-spie on 26 Apr 2023

Terms of Use: https://www.spiedigitallibrary.org/terms-of-use 


\title{
Conference Committee
}

\author{
Symposium Chairs
}

Armando Manduca, Mayo Clinic College of Medicine (United States)

Kevin R. Cleary, Georgetown University Medical Center (United States)

Conference Chairs

Berkman Sahiner, University of Michigan (United States)

David J. Manning, University of Cumbria (United Kingdom)

Program Committee

Craig K. Abbey, University of California, Santa Barbara (United States)

Kevin S. Berbaum, The University of lowa Hospitals and Clinics (United States)

Darrin C. Edwards, The University of Chicago (United States)

Brandon D. Gallas, U.S. Food and Drug Administration (United States)

Matthew A. Kupinski, College of Optical Sciences, The University of Arizona (United States)

Anthony J. Maeder, University of Western Sydney (Australia)

Claudia Mello-Thoms, University of Pittsburgh (United States)

David L. Wilson, Case Western Reserve University (United States)

\section{Session Chairs}

1 Novel Tools and Optimization

Darrin C. Edwards, The University of Chicago (United States)

2 Image Display

Anthony J. Maeder, University of Western Sydney (Australia)

3 Medical Imaging and Radiological Health:

Contributions of Dr. Robert F. Wagner

Kyle J. Myers, U.S. Food and Drug Administration (United States)

$4 \quad$ Eye Tracking and Human Visual System

David J. Manning, University of Cumbria (United Kingdom)

5 Model Observers

Darrin C. Edwards, The University of Chicago (United States) 
ROC

Kevin S. Berbaum, The University of lowa Hospitals and Clinics (United States)

7 Observer Performance

Brandon D. Gallas, U.S. Food and Drug Administration (United States)

8 Observer Performance in Mammography

Claudia Mello-Thoms, University of Pittsburgh (United States) 


\section{In Memoriam}

\section{Robert F. Wagner \\ 1938-2008}

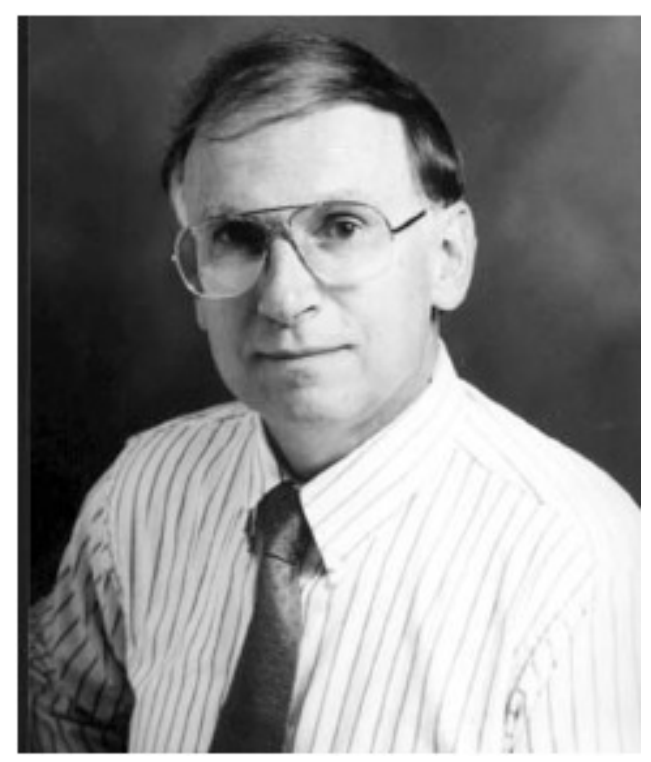

\section{A founding scientist and prolific contributor to modern medical imaging science and SPIE}

Robert F. "Bob" Wagner was a tremendous innovator in the field of medical imaging and image assessment methodologies. He was a key figure in the creation of the SPIE Medical Imaging symposium. An SPIE Fellow since 1988, Bob was active on the program committee of the Physics of Medical Imaging conference at the Medical Imaging symposium, and author of numerous technical papers published by SPIE.

"The medical imaging community has lost one of its founding fathers and most highly regarded members," said Kyle Myers, director of the Division of Imaging and Applied Mathematics at the Center for Devices and Radiological Health (CDRH), U.S. Food and Drug Administration (FDA). "Bob's career was dedicated to the development of consensus measurement methods for the assessment of medical imaging systems, quantitative medical imaging and tissue characterization, and computer-aided diagnosis. He earned an international reputation in these areas and applied his expertise to a wide range of regulatory issues central to the FDA's mission. He enlightened the scientific community within the agency as well as the international scientific community through the many invited presentations and tutorials he gave in and outside of the FDA, his numerous publications, his many professional society activities, and his assistance in regulatory decision making."

At this 2009 Medical Imaging symposium, a joint keynote session hosted by the CAD and Image Perception conferences honored Bob's many contributions from the early 1970s to the present through a series of presentations by some of his closest collaborators. 
David Brown (CDRH/FDA) recalled Bob's early years in the field, relating that after graduate and post-graduate work on the physics of nuclear interactions with radiation, Bob was hired by the Bureau of Radiological Health [a precursor to CDRH] to assess the dose reduction potential of radiographic intensifying screens made with phosphors developed in the color TV industry. Within three months he published a review of the relevant imaging literature from the medical, defense, consumer, and scientific communities, together with a charter for a laboratory program. Soon after, Bob introduced digital noise analysis to radiography, and showed that the new technology offered a 1.6- to 2.5-fold exposure reduction without compromising imaging performance. He then launched a program of inter-laboratory comparison of measurements on radiographic film samples that were circulated among fifteen commercial, government, and academic laboratories worldwide. In the process he became the prime mover for work toward consensus methodology for quantitative imaging performance measurements.

Mike Insana (Univ. of Illinois at Urbana-Champaign) shared memories of his years as Bob's post-doctoral student, working with Bob on the statistical characterization of ultrasound images. He described Bob as an exemplary mentor who shared his passion and joy for science.

Myers agreed, "Bob's greatest legacy may be the many young scientists he nurtured, who either worked directly under his tutelage at the FDA or otherwise benefitted from his unfailing patience and unselfish ease of availability."

Harry Barrett (Univ. of Arizona) began his presentation by relating noise-equivalent quanta (NEQ) - a concept central to Bob's unified approach to objective image performance assessment-to historical information-theoretic methods for evaluation of imaging systems. Barrett went on to describe the many ways in which NEQ was extended to address problems beyond the simple signal-known-exactly, background-knownexactly (SEK/BKE) task.

Ken Hanson (Los Alamos National Lab.) described his years of collaboration with Bob. He said they worked together, first in the area of noise characterization of radiographic and CT images and later on the evaluation of images confounded by artifacts. In this latter work, Bob and Ken pioneered the application of a decision theoretic approach to the assessment of image reconstruction algorithms, demonstrating that the common meansquare-error metric did not predict visual task performance as measured by detectability.

Bob's contemporary work, as described by Myers, "involved the consideration of the random effects associated with multiple readers of medical images and the logical extension of this work to the problem of the evaluation of multiple competing classifiers in statistical pattern recognition. Bob tackled problems of increasing complexity over the course of his career, relying throughout on the application of a unified, decision theoretic framework. In the process he brought about consensus on the importance of a taskbased approach to the objective assessment of imaging systems."

During more than forty years of professional life, Bob Wagner made numerous contributions to the field of medical imaging that significantly impacted academia, industry, and the FDA. His brilliant mind, incredible intuition, passion for science, sense of humor, charm, and warm friendship will be greatly missed. 